Российский эконолический университет ил. Г. В. Плеханова, г. Москва, Российская Федерация

Н. В. Рубцова

Байкальский государственный университет,

г. Иркутск, Российкая Федерация

\title{
СОЦИАЛЬНО-ЭКОНОМИЧЕСКАЯ ЭФФЕКТИВНОСТЬ ТУРИСТСКОЙ ДЕЯТЕЛЬНОСТИ: СОВРЕМЕННЫЕ ПОДХОДЫ К ИССЛЕДОВАНИЮ
}

\begin{abstract}
АНнотАция. Анализ современной экономической литературы показывает, что проблема исследования эффективности туристской деятельности в настоящее время является одной из дискутируемых и не в полной мере разработанных. В статье рассматриваются содержание и отличительные черты традиционного и широкого подходов, обосновывается целесообразность использования нового ( «сетевого») подхода, который отличается от имеющихся следующими положениями, отражающими современные представления о теории и методологии исследования социально-экономической эффективности туристской деятельности: расширяется содержание объекта исследования; углубляется содержание и усложняется природа предмета исследования; принимается во внимание, что эффективность взаимоотношений участников цепочки (сети) создания ценности туристского продукта является значимой составляющей социально-экономической эффективности туристской деятельности; изменяется ключевая задача управления эффективностью, которая заключается в поиске наиболее рационального способа достижения цели - лучшего состояния туристско-рекреационных систем по сравнению с предыдущим, определении баланса между входящими в данную систему элементами и самой системой в конкретный момент времени с использованием ограниченных ресурсов.

кЛЮЧЕВЫЕ СЛОВА. Социально-экономическая эффективность; туризм; туристская деятельность; туристско-рекреационная система.

ФИНАНСИРОВАНИЕ. Государственное задание № 2014/52 на выполнение работ в сфере научной деятельности в рамках проекта № 1841 «Активизация ресурсного потенциала Прибайкальского региона как фактора его устойчивого социально-экономического развития» (номер госрегистрации в ФГАНУ ЦИТиС 01201458900).

ИНФОРМАЦИЯ О СТАТЬЕ. Дата поступления 16 февраля 2016 г.; дата принятия к печати 26 февраля 2016 г.; дата онлайн-размещения 31 марта 2016 г.
\end{abstract}

M. A. Morozov G.V.Plekhanov Russian University of Economics, Moscow, Russian Federation

N. V. Rubtsova Baikal State University, Irkutsk, Russian Federation

\section{SOCIO-ECONOMIC EFFICIENCY OF TOURISM ACTIVITY: MODERN APPROACHES TO RESEARCH}

ABSTRACT. Analyses of modern economic literature shows that the problem of investigating tourism activity efficiency is currently the one to be under discussion and is not developed to the full. The article considers the content and peculiar features of the traditional and wide approaches, substantiates the practicality of using a new («net») approach which differs from the existing ones by the following statements that reflect modern ideas about the theory and methodology of investigating the socio-economic efficiency of tourism activity: the content of the target of research is expanding; the

(C) М. А. Морозов, Н. В. Рубцова, 2016

\section{Baikal Research Journal}


content is deepening and the nature of the research subject is complexifying; consideration is taken of the fact that relationship efficiency for participants of the chain (net) that creates the tourist product values is a significant component of the socio-economic efficiency of tourism activity; there arises a change of the key task of managing the efficiency which involves searching for the most rational way of achieving the target the best state of tourist-recreational systems in comparison with the previous ones, specifying the balance between the elements entering the system and the system itself at the particular moment of time with use of limited resources.

KEYWORDS. Socio-economic efficiency; tourism; tourist activity; system of tourism and recreation.

FINANCING. The governmental assignment No. 2014/52 for conducting works in the sphere of research activities within the base part of the project No. 1841 «Activation of the Baikal region resource potential as a factor of its sustainable economic development» (TsITiS FGANY registration No. 01201458900).

ARTICLE INFO. Received February 16, 2016; accepted February 26, 2016; available online March 31, 2016.

Возрастание роли туризма в экономике и общественной жизни государств, регионов, туристских дестинаций является важнейшей мировой тенденцией [1]. В связи с этим все более актуальным становится развитие методологии исследования эффективности туристской деятельности.

В настоящее время в контексте исследования эффективности туристской деятельности разработаны и практически используются два подхода: традиционный и широкий.

Наиболее распространенным является традиционный (или затратный) подход, основанный на оценке соотношения полученных экономических результатов с затратами, понесенными на их достижение, с помощью соответствующих показателей (рентабельность, фондоотдача, производительность труда, фондоемкость и т. д.) [2- 4]. Например, его использование нашло отражение в работах ряда отечественных авторов - Р. К. Аминовой [5], М. А. Морозова [6], Е. Н. Подсеваловой [7], Ю. В. Темного, Л. Р. Темной [8].

Среди зарубежных исследователей традиционный подход не менее популярен и используется, в частности, в рамках оценки технической (technical effi-ciency) и аллокативной эффективности (allocative efficiency) туристской деятельности [9-11]. Вместе с тем, его практическое применение (исходя из предлагаемых для оценки эффективности туристской деятельности показателей) обладает рядом ограничений: во-первых, использование чаще всего ограничивается оценкой деятельности конкретных хозяйствующих субъектов сферы рекреации и туризма; во-вторых, исключительно - экономического аспекта эффективности.

Широкий подход рассматривает данную категорию как соотношение полученного результата (эффекта) с желаемым ${ }^{1}[4 ; 12]$. Методология широкого подхода заключается в выявлении целей деятельности и оценке того, насколько полно они достигаются, или в измерении степени приближения к этим целям. Широкий подход наиболее удобен в случае оценки социального аспекта эффективности, поскольку он не предусматривает соотношения результатов деятельности с затратами на их

${ }^{1}$ Следует отметить, что в англоязычной экономической литературе употребляются два варианта термина «эффективность»: efficiency и effectiveness. Первый вариант (efficiency) соответствует традиционному подходу к исследованию эффективности, при этом в русскоязычных изданиях этот термин нередко переводится как «производительность». Второй вариант (effectiveness) - соотносится с широким подходом, и для интерпретации данного понятия часто используется термин «результативность» . Употребление разных детерминант в отношении одной категории «эффективность», на наш взгляд, позволяет четко разграничить подходы к пониманию сути и методологии ее исследования. Однако важно подчеркнуть, что базовое значение терминов «efficiency» и «effectiveness» все-таки «эффективность».

\section{Baikal Research Journal}


достижение, что подтверждается его применением при оценке социальной эффективности туризма в работах Н. Карауловой [13], С .Ю. Цехлы [14], Т. Ю. Чикуровой [15]. Данный подход использовался также Е. И. Юванен [16] и впоследствии Б. А. Осиповым, В. В. Соколенко, Ю. Д. Шмидтом [17] для оценки социально-экономической эффективности внутреннего туризма Приморского края. Кроме того, ряд исследователей используют целевой подход для оценки эффективности как показателя в составе других категорий. Например, Е. Н. Федосеева [18], В. И. Самарский [19] рекомендуют применять его при оценке эффективности предпринимательской деятельности санаторно-курортных организаций, а Т. П. Левченко - как один из показателей инвестиционной привлекательности здравниц [20].

Широкий подход получил большую популярность в исследовании эффективности туристско-рекреационных систем (ТРС), поскольку он позволяет рассматривать категорию «эффективность» не только в экономическом, но и, например, социальном, культурном, природоохранном и другом ракурсах. По мнению сторонников данного подхода, эффективность является комплексной социально-экономической категорией и представляет собой не соотношение результатов и затрат, а состояние социально-экономической системы [21]. Поскольку имеющиеся в распоряжении социально-экономической системы ресурсы всегда дефицитны (так как общая потребность в них всегда выше, чем совокупное предложение), то для реализации одних проектов зачастую приходится отказываться от других в силу ограниченности имеющихся ресурсов (например, финансовых, трудовых, природных и т. д.). Величина этого отказа характеризует размер альтернативных издержек, или точнее, альтернативной стоимости. Таким образом, система стремится к осуществлению оптимальной комбинации действий с помощью эффективной комбинации ресурсов, при которой достигается социально-экономический результат с минимальными альтернативными издержками [Там же], что и определяет содержание эффективности ее функционирования. Для того чтобы повысить свою эффективность, система вынуждена искать новые комбинации действий с использованием той же или новой (но все же ограниченной) комбинации ресурсов. Следовательно, повышение эффективности сводится к поиску наиболее рационального способа достижения цели, в определении баланса отношений между входящими в систему элементами и самой системой в конкретный момент времени [17; 21-23]. Широкий подход к трактовке эффективности свидетельствует, с одной стороны, о многогранности данной категории, с другой, о сложности ее представления в традиционных показателях и измерителях.

Разновидностью широкого подхода можно назвать «подход акционеров» (заинтересованных лиц, стейкхолдеров), который основан на утверждении, что для каждой деятельности существует группа лиц, по-своему заинтересованных в ее результатах. При этом показателями эффективности считается удовлетворенность этих заинтересованных групп [23]. В частности, данный подход использовался Д. Н. Марковым [24] при разработке методики оценки вклада туризма в макроэкономические показатели региона. Предложенная им методика позволяет оценить общий оборот предприятий туристской сферы от обслуживания туристских потоков, прямой и косвенный вклад туризма в валовой региональный продукт, а также уровень занятости и величину налогов и сборов, обеспеченных туристским потреблением [Там же]. Однако необходимо отметить, что предложенная им методика преследует цель оценки мультипликативного эффекта от вклада туризма в экономику региона, а не эффективности.

C формальных позиций нет противоречий между использованием традиционного или широкого подхода к исследованию эффективности туристской деятельности. Однако с содержательной точки зрения между ними можно заметить существенные различия. Эти различия проявляются в процессе моделирования деятельности ТРС, т. е. предвидения будущих процессов, событий, явлений, которые не всегда сопря-

\section{Baikal Research Journal}

электронный научный журнал Байкальского государственного университета 
жены с экономией используемых ресурсов. Вместе с тем, произошедшее в современной туристской науке расширение и усложнение содержания и целей функционирования сферы рекреации и туризма предопределяет исследование ее эффективности в социально-экономическом контексте, следовательно, использование широкого подхода становится все более востребованным.

В последние годы рядом российских исследователей предпринимаются попытки сформировать системы показателей и соответствующие методики для исследования эффективности туристской деятельности в социально-экономическом аспекте на разных уровнях управления.

В частности, Д. Новиков и М. Кричмарь, рассматривая эффективность туризма с позиции инновационной логистики, акцентируют внимание на том, что основу социально-экономической природы туристского продукта составляет комплексная туристская услуга, которая включает в себя две принципиально различные группы:

- услуги, обладающие абсолютной ценностью и самоцелью для их потребителей - использование рекреационных ресурсов, организация экскурсий, туристические маршруты, экстремальный туризм и т. д.;

- утилитарные услуги - транспортные, гостиничные, ресторанные и др.

В этой связи, по их мнению, «повышение эффективности туристского бизнеса... связано с более высоким уровнем организации текущего и стратегического управления совокупными потоковыми процессами в этой сфере» [25, с. 30]. Разработанные данными авторами коэффициенты эффективности позволяют оценить процесс логистизации (управления потоковыми процессами) туристической фирмы.

Авторским коллективом в составе М. А. Морозова, Н. С. Морозовой (2015) был разработан набор показателей для оценки эффективности деятельности субъектов Российской Федерации в сфере туризма. Предложенный набор объединяет показатели эффективности по следующим признакам: туристский поток, туристские услуги, гостиничные услуги, налоговые отчисления от туристской деятельности, инвестиционная деятельность в туризме, трудовые ресурсы в сфере туризма, инфраструктура туризма, вклад туризма в валовой региональный продукт, рекламная деятельность регионов по продвижению туризма, образование в сфере туризма, дополнительные характеристики [26].

Как представляется, при проведении конкретного анализа социально-экономической эффективности туристской деятельности целесообразно ограничить количество показателей, исходя из целей исследования. Кроме того, необходима выработка соответствующих критериев, согласно которым будет происходить отбор показателей по каждому из выделенных сторон и аспектов эффективности. Наряду с применением системы показателей, отражающих социально-экономическую эффективность туристской деятельности, целесообразно использование и обобщающего показателя, который можно рассматривать как индикатор оптимальности при выборе лучшего (приоритетного) варианта функционирования сферы рекреации и туризма, обеспечивающий оптимизационный подход в системе ее эффективного управления.

Вместе с тем, в современных усложняющихся условиях функционирования ТРС эффективность туристской деятельности целесообразно рассматривать в аспекте взаимодействия и взаимной координации субъектов сферы рекреации и туризма участников цепочки создания ценности туристского продукта ${ }^{2}$, поскольку социально-экономическая эффективность такой цепочки во многом зависит не столько от результата автономного функционирования каждого субъекта туристской деятельности, сколько от их взаимной координации и кооперации, т. е. эффективности взаимодействия (взаимоотношений).

${ }^{2}$ Подробнее о цепочке создания ценности туристского продукта см. [27].

\section{Baikal Research Journal}

электронный научный журнал Байкальского государственного университета 
Таким образом, можно говорить о возможности и необходимости использования нового подхода, который предполагает интерпретацию эффективности туристской деятельности посредством трех составляющих: экономическая, социальная и эффективность взаимоотношений [28].

Сравнительная характеристика методологии традиционного, широкого и "сетевого" подходов к исследованию эффективности туристской деятельности

\begin{tabular}{|c|c|c|c|}
\hline Характеристика & Традиционный & Широкий & Сетевой \\
\hline $\begin{array}{l}\text { Содержание } \\
\text { объекта иссле- } \\
\text { дования }\end{array}$ & $\begin{array}{l}\text { Экономическая дея- } \\
\text { тельность конкретных } \\
\text { хозяйствующих субъек- } \\
\text { тов туристско-рекреа- } \\
\text { ционных систем } \\
\end{array}$ & $\begin{array}{l}\text { Деятельность хозяй- } \\
\text { ствующих субъектов } \\
\text { туристско-рекреаци- } \\
\text { онных систем }\end{array}$ & $\begin{array}{l}\text { Деятельность цепочки (сети) } \\
\text { создания ценности турист- } \\
\text { ского продукта }\end{array}$ \\
\hline $\begin{array}{l}\text { Содержание } \\
\text { предмета иссле- } \\
\text { дования }\end{array}$ & $\begin{array}{l}\text { Эффективность - соот- } \\
\text { ношение результата и } \\
\text { затрат, обеспечивших } \\
\text { его достижение }\end{array}$ & $\begin{array}{l}\text { Эффективность (ре- } \\
\text { зультативность)- } \\
\text { соответствие полу- } \\
\text { ченных результатов } \\
\text { целям деятельности }\end{array}$ & $\begin{array}{l}\text { Эффективность - состояние } \\
\text { социально-Экономической } \\
\text { системы }\end{array}$ \\
\hline $\begin{array}{l}\text { Природа пред- } \\
\text { мета исследова- } \\
\text { ния }\end{array}$ & Экономическая & $\begin{array}{l}\text { Экономическая } \\
\text { Социальная } \\
\text { Социально-экономи- } \\
\text { ческая }\end{array}$ & $\begin{array}{l}\text { Социально-экономическая - } \\
\text { обобщающая характеристика } \\
\text { экономической, социальной } \\
\text { эффективности и эффектив- } \\
\text { ности взаимоотношений }\end{array}$ \\
\hline $\begin{array}{l}\text { Методологиче- } \\
\text { ская основа }\end{array}$ & $\begin{array}{l}\text { Соотношение полу- } \\
\text { ченных результатов с } \\
\text { затратами на их дости- } \\
\text { жение }\end{array}$ & $\begin{array}{l}\text { Соотношение полу- } \\
\text { ченных результа- } \\
\text { тов с ожидаемыми } \\
\text { (планируемыми) } \\
\text { әффектами } \\
\end{array}$ & $\begin{array}{l}\text { Соотношение состояния } \\
\text { туристско-рекреационных } \\
\text { систем с ожидаемым (плани- } \\
\text { руемым) состоянием }\end{array}$ \\
\hline $\begin{array}{l}\text { Содержание } \\
\text { туристско-ре- } \\
\text { креационных } \\
\text { систем } \\
\end{array}$ & $\begin{array}{l}\text { Деятельность отдель- } \\
\text { ных хозяйствующих } \\
\text { субъектов сферы рекре- } \\
\text { ации и туризма }\end{array}$ & $\begin{array}{l}\text { Совокупность само- } \\
\text { стоятельно функци- } \\
\text { онирующих хозяй- } \\
\text { ствующих субъектов }\end{array}$ & $\begin{array}{l}\text { Сеть взаимосвязанных акто- } \\
\text { ров, участвующих в процессе } \\
\text { создания ценности турист- } \\
\text { ского продукта }\end{array}$ \\
\hline $\begin{array}{l}\text { Цель управле- } \\
\text { ния эффектив- } \\
\text { ностью }\end{array}$ & $\begin{array}{l}\text { Достижение макси- } \\
\text { мального результата } \\
\text { при минимальных } \\
\text { издержках }\end{array}$ & $\begin{array}{l}\text { Соответствие или } \\
\text { превосходство полу- } \\
\text { ченных результатов } \\
\text { запланированным } \\
\text { (ожидаемым) }\end{array}$ & $\begin{array}{l}\text { Поиск наиболее рациональ- } \\
\text { ного способа достижения } \\
\text { цели, определение баланса } \\
\text { между входящими в систему } \\
\text { элементами и самой систе- } \\
\text { мой в конкретный момент } \\
\text { времени с использованием } \\
\text { ограниченных ресурсов }\end{array}$ \\
\hline \begin{tabular}{|l} 
Оптимум \\
эффективности \\
\end{tabular} & ( $\operatorname{Max}$ & $\geq 1$ & $\begin{array}{l}\text { Лучше предыдущего состо- } \\
\text { яния }\end{array}$ \\
\hline $\begin{array}{l}\text { Характеристика } \\
\text { используемых } \\
\text { показателей }\end{array}$ & $\begin{array}{l}\text { Экономические, коли- } \\
\text { чественные }\end{array}$ & $\begin{array}{l}\text { Количественные, } \\
\text { качественные, обоб- } \\
\text { щающие, интеграль- } \\
\text { ные }^{1}\end{array}$ & $\begin{array}{l}\text { Качественные, обобщающие, } \\
\text { интегральные }^{2}\end{array}$ \\
\hline Ограничения & $\begin{array}{l}\text { Может использовать- } \\
\text { ся только для оценки } \\
\text { экономической эффек- } \\
\text { тивности }\end{array}$ & Отсутствуют & $\begin{array}{l}\text { Использование ограничено } \\
\text { уровнем туристских дести- } \\
\text { наций, поскольку данный } \\
\text { уровень позволяет четко } \\
\text { обозначить границы сети соз- } \\
\text { дания ценности туристского } \\
\text { продукта }\end{array}$ \\
\hline
\end{tabular}

${ }^{1}$ Обобщающие и интегральные показатели могут строиться на основе использования экономических, количественных и качественных показателей.

${ }^{2}$ Социально-экономическая природа эффективности в рамках «сетевого» подхода не позволяет использовать при ее оценке только экономические и количественные показатели. Однако они могут применяться при формировании обобщающих или интегральных показателей.

\section{Baikal Research Journal}


Следует особо подчеркнуть, что смысл «сетевого» подхода заключается не в том, что добавляется новый аспект эффективности - эффективность взаимоотношений, а в том, что имеет место кумулятивный эффект. Под кумулятивным эффектом мы понимаем достижение социально-экономической эффективности туристской деятельности, обусловленное эффективным межфирменным взаимодействием субъектов сферы рекреации и туризма (эффективностью взаимоотношений). Кумулятивный эффект отличается от синергетического (системного) эффекта тем, что последний возникает в результате объединения элементов в систему и их совместной деятельности. Кумулятивный эффект - это эффект, являющийся результатом длительного взаимодействия субъектов сферы рекреации и туризма и возникающих при этом устойчивых отношенческих контрактов. Таким образом, синергетический эффект характеризует в большей степени результат объединения субъектов сферы рекреации и туризма (необходимого для формирования туристского продукта), а кумулятивный - качественный аспект этого объединения (эффективное взаимодействие субъектов сферы рекреации и туризма).

Следовательно, методологии «сетевого» подхода (в отличие от традиционного и широкого) присущи следующие специфические черты (табл.):

- расширяется содержание объекта исследования - туристская деятельность рассматривается как цепочка (сеть) создания ценности туристского продукта, т. е. исследование социально-экономической эффективности осуществляется не только применительно к отдельным хозяйствующим субъектам и соответствующим им отраслям, но и в аспекте их взаимодействия и взаимной координации;

- углубляется содержание предмета исследования - понятие «эффективность» рассматривается как состояние социально-экономической системы, при этом оптимумом эффективности считается лучшее состояние ТРС по сравнению с предыдущим;

- усложняется природа предмета исследования - категория «социально-экономическая эффективность» рассматривается в социальном и экономическом аспектах, а также в аспекте эффективности взаимоотношений участников цепочки (сети) создания ценности туристского продукта;

- принимается во внимание, что эффективность взаимоотношений участников цепочки (сети) создания ценности туристского продукта является значимой составляющей социально-экономической эффективности туристской деятельности в рамках конкретной туристской дестинации;

- изменяется ключевая задача управления эффективностью, которая заключается в поиске наиболее рационального способа достижения цели - лучшего состояния ТРС по сравнению с предыдущим, определении баланса между входящими в сферу рекреации и туризма элементами в конкретный момент времени с использованием ограниченных ресурсов.

Таким образом, изложенное свидетельствует, что «сетевой» подход можно рассматривать как перспективное направление, дополняющее и углубляющее методологию исследования социально-экономической эффективности туристской деятельности в современных TPC.

\section{Список использованной литературы}

1. Суходолов А. П. История, современное состояние и перспектива развития индустрии туризма (в мире, России и Иркутской области) / А. П. Суходолов // Иркутский историко-экономический ежегодник. 2011. - Иркутск : Изд-во БГУЭП, 2011. - С. 85-92.

2. Слободняк И. А. Методологические основы оценки эффективности деятельности учреждения / И. А. Слободняк, О. А. Преина. - Иркутск : Изд-во БГУЭП, 2014. - 152 с.

3. Морозова Н. С. Предпринимательство и конкуренция в туризме : монография / Н. С. Морозова, М. А. Морозов. - М. : РосНОУ, 2010. - 136 с.

\section{Baikal Research Journal}


4. Рубцова Н. В. Социально-экономическая эффективность туристской деятельности: теория, методология, практика / Н. В. Рубцова. - Иркутск : Изд-во БГУЭП, 2015. - 212 с.

5. Аминова Р. К. Методические основы оценки и направления повышения эффективности функционирования организаций индустрии туризма : автореф. дис. ... канд. экон. наук : 08.00.05 / Р. К. Аминова. - Махачкала, 2009. - 22 с.

6. Морозов М. А. Экономика и предпринимательство в социально-культурном сервисе и туризме / М. А. Морозов. - М. : Академия, 2008. - 288 с.

7. Подсевалова Е. Н. Методические подходы к определению эффективности предприятий туриндустрии / Е. Н. Подсевалова // Сервис в России и за рубежом. - 2011. — № 3. С. $160-168$.

8. Темный Ю. В. Экономика туризма / Ю. В. Темный, Л. Р. Темная. - М. : Инфра-М, 2010. -448 c.

9. Barros C. P. Evaluating the efficiency of a small hotel chain with a Malmquist productivity index / C. P. Barros // International Journal of Tourism Research. -2005. — № 7 (3). — P. $173-184$.

10. Barros C. P. Productivity in tourism industry / C. P. Barros, P. Alves // International Advances in Economic Research. - 2003. - № 10 (3). - P. 215-225.

11. Barros C. P. Technical and allocative efficiency in a chain of small hotels / C. P. Barros, M. J. Mascarenhas // International Journal of Hospitality Management. — 2005. — № 24 (3). P. 415-436.

12. Экономика туризма : учебник / М. А. Морозов, Н. С. Морозова, Г. А. Карпова, Л. В. Хорева. - М. : Федер. агентство по туризму, 2014. - 320 с.

13. Караулова Н. Внешнеэкономическая деятельность предприятия туризма: система показателей эффективности хозяйственной деятельности предприятия / Н. Караулова // Вестник Хабаровской государственной академии экономики и права. - 2007. — № 3 (30). - С. $63-68$.

14. Цехла С. Ю. Особенности оценки социальной эффективности туристической деятельности / С. Ю. Цехла / Экономика Крыма. - 2010. — № 2 (31). — С. 78-82.

15. Чикурова Т. Ю. Социально-экономическая эффективность туристской деятельности в малых и средних городах : автореф. дис. ... канд. экон. наук : 08.00.05 / Т. Ю. Чикурова. Екатеринбург, 2011. - 25 с.

16. Юванен Е. И. Оценка социально-экономической эффективности внутреннего туризма в регионе (на примере Приморского края) : автореф. дис. ... канд. экон. наук : 08.00.05/ Е. И. Юванен. - Владивосток, 2006. - 22 с.

17. Осипов Б. А. Методика оценки социально-экономической эффективности внутреннего туризма / Б. А. Осипов, В. В. Соколенко, Ю. Д. Шмидт // Вестник Тихоокеанского государственного экономического университета. - 2011. - № 3. - С. 3-11.

18. Федосеева Е. Н. Оценка эффективности предпринимательской деятельности организаций санаторно-курортной сферы : автореф. дис. ...канд. экон. наук : 08.00.05 / Е. Н. Федосеева. - СПб., 2010. - 26 с.

19. Самарский В. И. Методические подходы к развитию предпринимательской деятельности организаций санаторно-курортной сферы : автореф. дис. ... канд. экон. наук : 08.00.05/ В. И. Самарский. - Сочи, 2011. - 23 с.

20. Левченко Т. П. Управление инвестиционной привлекательностью организаций санаторно-курортной сферы : автореф. дис. ... д-ра экон. наук : 08.00.05 / Т. П. Левченко. — СПб., 2004. - $32 \mathrm{c}$.

21. Социально-экономическая эффективность регионального развития / С. Н. Растворцева, В. В. Фаузер, В. Н. Задорожный, В. А. Залевский. - М. : Экон-Информ, 2011. - 134 с.

22. Парето В. Компендиум по общей социологии / В. Парето ; пер. с итал. А. А. Зотова. М. : ГУ ВШЭ, 2007. - 511 с.

23.Рубцова Н. В. Эффективность сервисной деятельности / Н. В. Рубцова. - Иркутск : Изд-во БГУЭП, 2011. - 173 с.

24.Марков Д. Н. Экономическая оценка туристской деятельности на региональном уровне : атореф. дис. ... канд. экон. наук : 08.00.05 / Д. Н. Марков. - Владивосток, 2013. - 24 с.

25. Новиков Д. Инновационная логистика в туризме / Д. Новиков, М. Кричмарь // РИСК: ресурсы, информация, снабжение, конкуренция. - 2006. - № 3. - С. 30-31.

26. Морозов М. А. Формирование системы показателей для оценки эффективности деятельности регионов в сфере туризма / М. А. Морозов, Н. С. Морозова // Sochi Journal of Economy. - 2015. — № 2 (35). - C. 105-115.

\section{Baikal Research Journal}

электронный научный журнал Байкальского государственного университета 
27. Рубцова Н. В. Цепочка создания ценности туристского продукта / Н. В. Рубцова // Региональная экономика: теория и практика. - 2012. — № 40 (271). - С. 46-53.

28. Рубцова Н. В. Содержание понятия эффективность туристской деятельности / Н. В. Рубцова // Региональная экономика: теория и практика. - 2012. — № 18 (249). — С. 54-60.

\section{References}

1. Sukhodolov A. P. History, current state and prospects of developing tourism industry (in the world, Russia and Irkutsk Oblast) Irkutskii istoriko-ekonomicheskii ezhegodnik. 2011 [Irkutsk Historical and Economic Yearbook. 2011]. Irkutsk, Baikal State University of Economics and Law Publ., 2011, pp. 85-92. (In Russian).

2. Slobodnyak I. A., Preina O. A. Metodologicheskie osnovy otsenki effektivnosti deyatelnosti uchrezhdeniya [Methodological basics of institution performance evaluation]. Irkutsk, Baikal State University of Economics and Law Publ., 2014. $152 \mathrm{p}$.

3. Morozova N. S., Morozov M. A. Predprinimatel'stvo i konkurentsiya v turizme [Entrepreneurship and competition in tourism]. Moscow, Russian New University Publ., 2010. $136 \mathrm{p}$.

4. Rubtsova N. V. Sotsial'no-ekonomicheskaya effektivnost' turistskoi deyatel'nosti: teori ya, metodologiya, praktika [Socio-economic efficiency of tourism activity: theory, methodology, practice]. Irkutsk, Baikal State University of Economics and Law Publ., 2015. 212 p.

5. Aminova R. K. Metodicheskie osnovy otsenki i napravleniya povysheniya effektivnosti funktsionirovaniya organizatsii industrii turizma. Avtoref. Kand. Diss. [Methodical basics of assessment and directions of increasing efficiency of functioning for tourism industry businesses. Cand. Diss. Thesis]. Makhachkala, 2009. 22 p.

6. Morozov M. A. Ekonomika i predprinimatel'stvo $v$ sotsial'no-kul'turnom servise i turizme [Economy and entrepreneurship in socio-cultural service and tourism] Moscow, Akademiya Publ., 2008. 288 p.

7. Podsevalova E. N. Methodological approaches to identifying efficiency of tourism industry businesses. Servis v Rossii $i$ za rubezhom $=$ Service in Russia and Abroad, 2011, no. 3, pp. 160-168. (In Russian).

8. Temny Yu. V., Temnaya L. R. Ekonomika turizma [Tourism economy]. Moscow, Infra-M Publ., 2010. 448 p.

9. Barros C.P. Evaluating efficiency of a small hotel chain using the Malmquist productivity index. International Journal of Tourism Research, 2005, no. 7 (3), pp. 173-184. (In Russian).

10. Barros C. P., Alves P. Productivity in tourism industry. International Advances in Economic Research, 2003, no. 10 (3), pp. 215-225. (In Russian).

11. Barros C. P., Mascarenhas M. J. Technical and allocative efficiency in a chain of small hotels. International Journal of Hospitality Management, 2005, no. 24 (3), pp. 415-436. (In Russian).

12. Morozov M. A., Morozova N. S., Karpova G. A., Khoreva L. V. Ekonomika turizma [Tourism economy]. Moscow, Federal Agency for Tourism Publ., 2014. 320 p.

13. Karaulova N. Foreign economic activity of the tourism business: system of efficiency indicators for economic activity of the business. Vestnik Khabarovskoi gosudarstvennoi akademii ekonomiki i prava = Bulletin of Khabarovsk State Academy of Economics and Law, 2007, no. 3 (30), pp. 63-68. (In Russian).

14. Tsekhla S. Yu. Features of assessing social efficiency of tourism activity. Ekonomika Kryma $=$ Economy of Crimea, 2010, no. 2 (31), pp. 78-82. (In Russian).

15. Chikurova T. Yu. Sotsial'no-ekonomicheskaya effektivnost' turistskoi deyatel'nosti $v$ malykh i srednikh gorodakh. Avtoref. Kand. Diss. [Socio-economic efficiency of tourist activity in small and middle-sized towns. Cand. Diss. Thesis]. Ekaterinburg, 2011. 25 p.

16. Yuvanen E. I. Otsenka sotsial'no-ekonomicheskoi effektivnosti vnutrennego turizma $v$ regione ( na primere Primorskogo kraya). Avtoref. Kand. Diss. [Assessing socio-economic efficiency of domestic tourism in the region (using the example of Primorsky Territory). Cand. Diss. Thesis]. Vladivostok, 2006. $22 \mathrm{p}$.

17. Osipov B. A., Sokolenko V. V., Shmidt Yu. D. Methods of assessing socio-economic efficiency of domestic tourism. Vestnik Tikhookeanskogo gosudarstvennogo ekonomicheskogo universiteta $=$ Bulletin of Pacific State University of Economics, 2011, no. 3, pp. 3-11. (In Russian).

18. Fedoseyeva E. N. Fedoseyeva E. N. Otsenka effektivnosti predprinimatel'skoi deyatel'nosti organizatsii sanatorno-kurortnoi sfery. Avtoref. Kand. Diss. [Assessing efficiency of business

\section{Baikal Research Journal}


activities of organizations of the sanitary and health resort sphere. Cand. Diss. Thesis]. Saint Petersburg, 2010. $26 \mathrm{p}$.

19. Samarsky V. I. Metodicheskie podkhody $k$ razvitiyu predprinimatel'skoi deyatel'nosti organizatsii sanatorno-kurortnoi sfery. Avtoref. Kand. Diss. [Methodical approaches to developing business activities of organizations of the sanitary and health resort sphere. Cand. Diss. Thesis]. Sochi, 2011. $23 \mathrm{p}$.

20. Levchenko T. P. Upravlenie investitsionnoi privlekatel'nost'yu organizatsii sanatorno-kurortnoi sfery. Avtoref. Kand. Diss. [Management of investment attractiveness of sanitary and health resort organizations. Cand. Diss. Thesis]. Saint Petersburg, 2004. 32 p.

21. Rastvortseva S. N., Fauzer V. V., Zadorozhny V. N., Zalevsky V. A. Sotsial'no-ekonomicheskaya effektivnost' regional'nogo razvitiya [Socio-economic efficiency of regional development]. Moscow, Ekon-Inform Publ., 2011. 134 p.

22. Pareto V. Compendium of General Sociology. Minneapolis, University of Minnesota press, 1980. 471 p. (Russ. ed.: Pareto V. Kompendium po obshchei sotsiologii. Moscow, Higher School of Economics Publ., 511 p.).

23. Rubtsova N. V. Effektivnost' servisnoi deyatel'nosti [Efficiency of service activity]. Irkutsk, Baikal State University of Economics and Law Publ., 2011. 173 p.

24. Markov D. N. Ekonomicheskaya otsenka turistskoi deyatel'nosti na regional'nom urovne. Avtoref. Kand. Diss. [Economic estimation of tourism activity at the regional level. Cand. Diss. Thesis]. Vladivostok, 2013. 24 p.

25. Novikov D., Krichmar' M. Innovative logistics in tourism. Logistics Innovation in Tourism. RISK: resursy, informatsiya, snabzhenie, konkurentsiya $=$ RISC: Resources, Information, Supply, Competition, 2006, no. 3, pp. 30-31. (In Russian).

26. Morozov M.A., Morozova N. S. Developing system of indicators for assessing efficiency of regional activities in the tourism sector. Formation of System of Indicators to Assess Effectiveness of Regional Tourism. Sochi Journal of Economy, 2015, no. 2 (35), pp. 105-115. (In Russian).

27. Rubtsova N. V. Chain of creating tourist product values. Regionalnaya ekonomika: teoriya i praktika = Regional Economy: Theory and Practice, 2012, no. 40 (271), pp. 46-53. (In Russian).

28. Rubtsova N. V. Content of the concept of tourism activity efficiency. Regionalnaya ekonomika: teoriya i praktika = Regional Economy: Theory and Practice, 2012, no. 18 (249), pp. 54-60. (In Russian).

\section{Информация об авторах}

Морозов Михаил Анатольевич - доктор экономических наук, профессор, кафедра гостиничного и туристического бизнеса, Российский экономический университет им. Г. В. Плеханова, 117997, г. Москва, Стремянный пер., 36, e-mail: mmorozov@bk.ru.

Рубиова Наталья Владимировна - кандидат экономических наук, доцент, кафедра менеджмента, маркетинга и сервиса, Байкальский государственный университет, 664003, г. Иркутск, ул. Ленина, 11, e-mail: runatasha21@yandex.ru.

\section{Authors}

Mikhail A. Morozov - Doctor habil. (Economics), Professor, Chair of Hotel and Tourism Business, G. V. Plekhanov Russian University of Economics, 36 Stremyanny lane, 117997, Moscow, Russian Federation; e-mail: mmorozov@bk.ru.

Natalya V. Rubtsova - PhD in Economics, Associate Professor, Chair of Management, Marketing and Services, Baikal State University, 11 Lenin St., 664003, Irkutsk, Russian Federation; e-mail: runatasha21@yandex.ru.

\section{Библиографическое описание статьи}

Морозов М. А. Социально-экономическая эффективность туристской деятельности: современные подходы к исследованию / М. А. Морозов, Н. В. Рубцова // Baikal Research Journal. - 2016. — T. 7, № 2. — DOI : 10.17150/2411-6262.2016.7(2).13.

\section{Reference to article}

Morozov M. A., Rubtsova N. V. Socio-economic efficiency of tourism activity: modern approaches to research. Baikal Research Journal, 2016, vol. 7, no. 2. DOI: 10.17150/24116262.2016.7(2).13. (In Russian).

\section{Baikal Research Journal}

